\title{
Sawbones no longer?
}

\author{
Stephen Hancocks OBE \\ Editor-in-Chief
}

Every now and then the world in general and microcosms of the world in particular, dentistry for example, have the benefit of rubbing shoulders with a visionary. Some years ago Dr David Barmes of the World Health Organisation, who in the late 1970s came up with the idea of oral health goals for the year 2000 and who plucked the desired measure of three decayed, missing or filled teeth (DMFT) at 12 years of age apparently out of thin air, made a rather startling prediction. Much to the bewilderment of an international audience of dentists he opined that in the future we would become dental or oral physicians rather than dental surgeons. It was one of those occasions when everyone was so surprised that no one thought to question it further in case it was impolite to do so or in the event that he perhaps hadn't quite got his facts straight.

Neither circumstance applied. David had thought it through very thoroughly. His argument was that far from continuing to cut out pieces of diseased hard tissue and additional sufficient sound tissue in order to make a mechanically retentive restoration we would instead be looking at healing demineralised enamel and dentine with fluoride, preserving otherwise compromised tissue with minimally invasive techniques and materials and providing a far more holistic approach to oral health. His words stunned me too at the time but I was happily reminded of them when reading the research paper in this issue on the medical and dental attendance of patients in an area of the UK. ${ }^{1}$

\section{THE PERSONAL TOUCH}

Not only are we heading towards, indeed are already achieving, that predicted role of oral physician we are also, I suggest, entering into an era that seemed wholly alien to us only a handful of years ago, that of being a wider health advisor to our patients.

With links between systemic and oral disease becoming more apparent almost by the day it is hardly surprising that this might be the case. I have argued previously that the natural progression from providing smoking cessation advice is that of broaching the matter of alcohol consumption. Yet coming up rapidly on the outside curve is the suggestion that obesity will be the next subject to tackle head-on with our patients. But are all these areas really our job? Surely we inhabit a smaller, more discrete and discreet area of health care? Possibly not ever and probably not now; we just hadn't thought it through.

One of the barriers frequently described by dental clinicians in relation to giving tobacco cessation advice is that it is not their responsibility; it is often considered too personal, or none of 'our' business. Yet it has as direct a bearing on oral health as any other 'personal' habit, which admittedly includes diet and quite overwhelmingly encompasses oral hygiene. How much more personal can one get? And if diet is to be included then tackling obesity or at the very least acknowledging that it is a problem area surely has to be a logical step. In this regard, I understand that sales of 'bariatric' dental chairs (those of a greater size and capable of taking far greater weight) are booming. It is not only aircraft seats that are having to be 'upsized'.

For all its logicality in terms of health outcomes, it is a rather unsettling prospect. When the FDI embraced a tobacco cession section within its organisation in the mid-1990s it seemed a somewhat radical departure and yet the intervening decade or so has seen remarkable strides in this aspect of dental practice, with morbidity inevitably reduced and lives doubtless saved. Who would have thought that? Projecting ahead therefore, the possibilities of linking the role of oral physician with a wider responsibility for more attention to the parish of the general physician may also be a realistic and desirable, if slightly scary, prospect.

If one area of reticence, that we might have hitherto hidden behind, was the argument that patients really are not accustomed to it, ready for it or indeed are resistant to it then this is being rapidly eroded. Clearly patients are very comfortable with being asked these questions when the relevance of the information is explained to them, or indeed if they have encountered the logic of them via the internet or the increasing emphasis on oral and systemic health in articles, magazines and on television. Their expectations of us are actually far greater than we had perhaps reasonably given ourselves credit for. This should not be so surprising. Our regular patients, by definition, return to us when there is nothing wrong with them, as far as they know, which is a behaviour that they do not undertake with their general medical practitioner. Their trust in us to diagnose oral conditions is deeply held and there is every reason to believe that because of that faith they are also happy with the idea that we may be able to detect other health conditions, not necessarily to treat them but certainly to alert and refer. These are further indicators of the changes to come in dental practice in the years ahead, from reducing our role as sawbones and increasing our function in the diagnosis of sore bones.

1. Ireland, R S, Bowyer V, Ireland A, Sutcliffe P. The medical and dental attendance pattern of patients attending general dental practices in Warwickshire and their general health risk assessment. Br Dent J 2012; 212: E12.

DOI: $10.1038 /$ sj.bdj.2012.316 